\title{
Role of Smart Small and Medium Enterprises in the Development of Smart Cities: Case of Casablanca Smart-City Project - Morocco
}

\author{
Hanane Rochdane*, Siham Hamdani \\ Ecole Nationale de Commerce et de Gestion de Casablanca, Casablanca Morocco. \\ * Corresponding author. Tel.: 00212662090052; email: h.rochdane@yahoo.fr \\ Manuscript submitted June 10, 2017; accepted February 2, 2018. \\ doi: 10.17706/ijeeee.2018.8.3.181-186
}

\begin{abstract}
Beyond the fashion effect, the smart city phenomenon has become a good indicator of the dynamism of a modern, more communicative and responsible city. Many companies have taken part in this evolution either by their natural positioning such as Orange or by a technical capacity to carry this change (IBM, Cisco ...). But what about the others, in particular small and medium enterprises (SMEs)? The purpose of this paper is to study the role of smart SMEs in the development of smart cities based on the case of Casablanca; a city in the works to turn into a smart city and where SMEs represent the nerve center of the economy. More specifically, the purpose of this study is to establish a correlation between economic intelligence (EI) practices in SMEs and the development of smart cities based on the collaborative approach. The results showed that EI is still embryonic in the case of SMEs located in Casablanca mainly due to cultural and organizational factors. SMEs need therefore to change their working methods to overcome those factors and take part in the smart city ecosystem. In that, we support the progressive vision which puts people at the forefront rather than considering that digital technologies alone can transform and improve cities.
\end{abstract}

Key words: Collaborative approach, economic intelligence (EI), smart-city, SME.

\section{Introduction}

In recent years, the smart city has been a concept that fuels many elected officials speeches when it comes to issues of growth, efficiency and prosperity of tomorrow's cities. The City of Casablanca, is not left out as it was awarded the IEEE Smart City Initiative on the basis of a smart, frugal, social and sustainable city concept based on establishing public-private-populations partnerships, enabling citizens to be real players in the construction of the city of tomorrow. The Casablanca smart city project is therefore a stake for the city, its citizens and also its businesses [1]. The slogan of the last "Casablanca smart city expo" edition was "The city by all", whence the central question of this paper: What is the role of smart SMEs in the development of smart cities: case of the city of Casablanca?

The purpose of this study is to establish a correlation between economic intelligence (EI) practices in SMEs and the development of smart cities. It consists of identifying and describing accurately those practices through a descriptive quantitative study. SMEs constitute the nerve center of the Moroccan economy, as they represent $90 \%$ of overall enterprises but only $20 \%$ of created added value [2]. In order to face the challenges of globalization, their competitiveness is a must. As such, they need new management 
methods placing innovation at the heart of their strategies. According to [3], legal protection systems embodied in the international agreements are no longer sufficient to act as entry barriers, while counterfeiting accounts for a significant share of global trade.

This paper is structured as follows: first, we will take a global view of EI as a practice serving the company's strategic management, its competitiveness, as well as its impact on the emergence and development of smart cities. Then, we will describe EI practices by analyzing the results of the survey conducted among a sample of 210 SMEs located in Casablanca and working in the tertiary sector. Based on this analysis, we will project on the prospects of the emergence and development of Casablanca smart city using the collaborative approach and a framework as a proposal to understand how smart cities relate to smart SMEs.

\section{Literature Review}

Informing refers to providing representations to solve problems, given that these representations must be adapted to the context of use. Information is what brings us knowledge, which alters our worldview and reduces our uncertainty. It is relevant when it obeys quantitative, qualitative and temporal criteria [4]. This is what will be specified few years later by [5], emphasizing that EI includes all operations monitoring the competitive environment (protection, watch, influence) and thus is different from traditional intelligence. Information reliability and credibility are therefore a major challenge for any company. In that, [6] argue about intelligence as the ability to strategically venture into the uncertain, the ambiguous, the random by seeking and using maximum certainty, precision, and information.

A rigorous implementation of EI principles in companies contributes to the intelligence of the territories in which they operate. The smart city concept consists actually of using information and communication technologies (ICTs) to respond to environmental, social and economic challenges posed by cities growth. That is, using these technologies to improve the efficiency and quality of public services while lowering their costs and achieving a sustainable development model [7]-[11].

Since its appearance in the late 90s, the smart city concept was quickly captured by a number of multinational ICT companies which have considerably contributed to its dissemination and development [12]. The trademark "Smarter Cities" registered by IBM in 2011 represents a turning point in the visibility struggle ICT companies have engaged in. Today, IBM is a leading player in the development of systems supporting smart cities: data collection, security management, public transport management and energy distribution. These systems are currently used in several major cities around the world, including New York, Madrid and Chicago [12]. According to some authors, this appropriation by the business community has contributed to the concept's limited perception, while its definition still does not reach consensus in the scientific community [12]. Thus, the smart city is a fuzzy concept that has no single models or definitions.

However, the smart city concept is generally presented as a solution to certain aspects of the four dimensions of sustainable development (economic, environmental, social and governance). This is why the functional model as in [13] is widely recognized. According to this model, smart cities can be categorized according to six main criteria: smart economy, smart mobility, smart environment, smart people, smart living, and smart governance.

\section{Research Model and Hypothesis}

To analyze the impact of smart companies on the development of smart cities, we will consider the criterion of smart economy, which refers to the overall city competitiveness in terms of its innovative approach to R\&D, labor market flexibility, entrepreneurship opportunities and city leadership at the national and international levels [13]. Smart city theorists argue that cities are characterized by a dynamic 
economy for two reasons: on the one hand, promoting the "smart city" label attracts companies and the creative class to come and settle in. On the other hand, their presence and their proximity (for example by grouping them geographically into clusters) would encourage the innovation of products and services that would benefit both the city and businesses [14]. These notions were extensively addressed in the concept of creative city and creativity class [15], which [14] considers to be related to the smart city concept.

To make cities more intelligent, two categories of tools are distinguished in the literature: methodological tools for developing and implementing new technologies in the city; and technologies themselves (infrastructure, sensors and applications communicating, accessing, storing, manipulating, producing and transmitting information in all forms). In other words, the emergence of the smart city corresponds to an exponential production of data, the "Big Data" involving considerable technological, political, economic and commercial stakes. This mass of information offers many opportunities for companies, including SMEs, to better understand their markets and know their competitors. In addition, these big data can also present unprecedented opportunities to bring decision-makers and planners closer to citizens. This ideal corresponds to the desire for an open, transparent and collaborative city [16].

In this context, we consider the collaborative approach to provide an explanation and analysis of the relationship between smart cities and smart SMEs. "Collaboration goes beyond communication, cooperation, and coordination. It means "work together". It is a mutually beneficial relationship between two or more parties to achieve common goals by sharing responsibility, authority, and accountability for achieving results. It goes beyond sharing information or cooperating or coordinating to achieve each party's own goals. The purpose of collaboration is to create a shared vision and joint strategies to address concerns that go beyond the purview of any particular party" [17].

We propose a framework based on a bidirectional link between smart cities and smart SMEs:
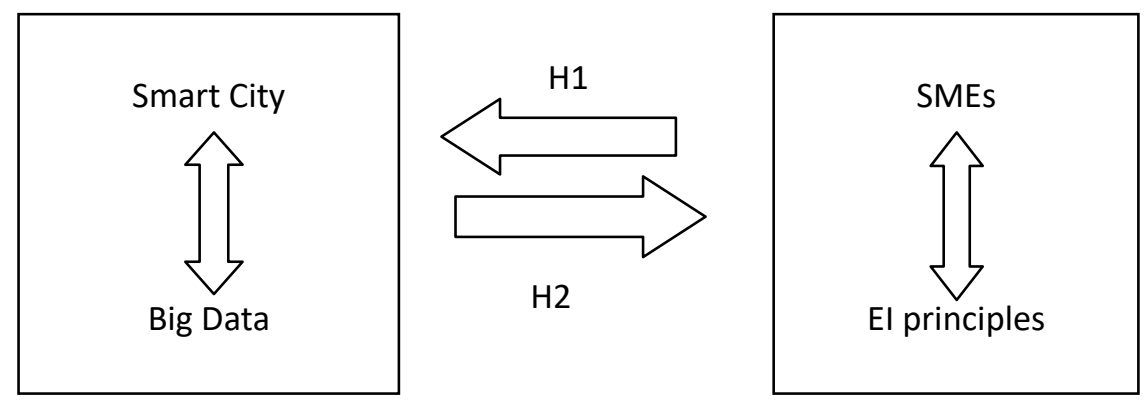

Fig. 1. Research model.

Hypothesis 1 (H1): Implementing EI principles in companies contributes to the intelligence of the territories in which they operate.

Hypothesis 2 (H2): Smart cities deployment is an economic opportunity for SMEs.

\section{Data Analysis and Results}

The framework proposed in the previous section suggests that smart cities, big data and businesses have a mutually reinforcing relationship. In order to improve mobility, manage energy consumption and secure the population, smart cities rely on the exploitation of digital technologies currently in full growth, such as smartphones and tablets, social networks, mobile applications, and especially connected objects. These objects are equipped with sensors and connected to the Internet. Once connected, they produce and receive massive amounts of data; the big data. In addition to the "volume" aspect, big data is defined by other characteristics such as high velocity, wide variety of data and most of all their great value in terms of sample completeness, accuracy, and relational nature [18]. Thus, when data has been accumulated over a period of 
time, it is possible to not only make descriptive analysis but also predictive analysis (to obtain the probability that an event $\mathrm{X}$ will occur in the future), and prescriptive analysis (to obtain the probability of the results at time T1 of a decision taken at time T0) [19], [20]. In short, the connection, integration and analysis of produced and transmitted data by connected objects provide a more coherent and intelligent understanding of the city, enabling businesses to provide in turn economic and innovative value benefiting the smart city and its citizens [21], [22].

On the other hand, while SMEs, in particular traditional SMEs, can actually exploit big data, the real difficulty is more on the side of know-how: which data should be exploited and how to make it a competitive advantage? The implementation of IE principles is therefore essential to exploit the power of big data and make the most relevant decisions. This is how SMEs will turn smart.

The survey of 210 SMEs located in Casablanca to describe their EI practices shows that due to cultural and organizational reasons, the selected SMEs face difficulties in implementing active security policies. They also neglect monitoring the economic environment, the voluntary sector as well as international actors. Finally, regarding influence and competitiveness, more than $67 \%$ of SMEs have quality products, but are likely to face difficulties selling them, while $91 \%$ of managers believe their companies have a good level of competitiveness without implementing influence mechanisms. It appears then that EI is still embryonic in the case of SMEs located in Casablanca. Consequently, it is very early to analyze their role in the development of Casablanca smart city. But at this stage, smart city initiatives and the e-Madina cluster officially launched in April 2015 would probably push SMEs towards this "new state of mind" which is EI to find their place in the middle of digital revolution and benefit from the smart city ecosystem.

Beyond interoperable, open and secure infrastructures, this implies a desire to "work together" in order to "live better together"; a desire to transform working methods and overcome cultural and organizational barriers. In other words, management styles, corporate culture and the positive involvement of the human factor are the real ingredients for the success of such project. In that, we share the progressive vision as in [14], which puts people at the forefront rather than considering that digital technologies alone can transform and improve cities. More specifically, [14] suggests that a city would be smart when information and digital technologies are used to educate, mobilize and encourage citizens to engage in policy debates around the future of their living environment [14]. Reference [8] also emphasizes that cities would become smart when investments in social (institutional and human) and technological infrastructure would promote sustainable development and improve its residents quality of life. For this last representation of the smart city, we hold that technological infrastructure is essential, but not sufficient.

\section{Conclusion}

In conclusion, if Casablanca is in progress to achieve the smart city status, SMEs need to consider seriously the implementation of EI principles. Certainly, the deployment of the smart city ecosystem is an economic opportunity for Casablanca's SMEs, they must think about creating a digital offer adapted to the new needs of the smart city. Due to entry barriers, they would benefit from working with larger groups to better respond to public tenders. Indeed, the intelligence of an emerging city like Casablanca is mainly linked to its infrastructure in terms of transportation, energy, and technology. However, we support the progressive vision as in [14] arguing that these infrastructures are not sufficient. Components such as human capital are considered decisive for smart urban development in increasingly competitive situations [23]. Finally, this paper does not present a full answer on the links between smart cities and smart SMEs, but opens up discussions about the human factor as a central element of a sustainable smart city. Therefore, future research must explore the smart city as a "system of socio-technical innovation." 


\section{References}

[1] Smart City Africa Casablanca. (2016). Bilan première édition pour des villes ouvertes, inclusives et innovantes.

[2] Ayegou, J., \& Rochdane, H. (2009). Les PME marocaines face à la mondialisation: Quelles opportunités du système de franchise ? In. La vulnérabilité des TPE et des PME dans un environnement mondialisé. 11es Journées scientifiques du Réseau Entrepreneuriat, 27-29.

[3] Lepère, C., \& Marcoux, J.-C. (2011). Small business intelligence. Edipro, Belgique.

[4] Reix, R. (2004). Systèmes d'information et management des organisations. Edition Vulbert, 5ème édition.

[5] Harbulot, C., \& Delbecque, E. (2011). La guerre économique. Edition: PUF.

[6] Morin, E., \& Moigne, J.-L. (1999). L’Intelligence de la complexité. Edition: l'Harmattan.

[7] Attour, A., \& Rallet, A. (2014). Le rôle des territoires dans le développement des systèmes trans-sectoriels d'innovation locaux : Le cas des smart cities. Innovations, 43, 253-279.

[8] Bakici, T., Almirall, E., et al. (2013). A smart city initiative: The case of Barcelona. Journal of Knowledge Economy, 4(2), 135-148.

[9] Caragliu, A., Bo, C., \& Nijkamp, P. (2009). Smart cities in Europe. Journal of Urban Technology, 18(2), 65-82.

[10] Santis, R., Fasano, A., Mignolli, N., \& Villa, A. (2014). Smart city: Fact and fiction. Retrieved from the website: https://mpra.ub.uni-muenchen.de/54536/1/MPRA_paper_54536.pdf

[11] Nam, T., \& Pardo, T. A. (2011). Conceptualizing smart city with dimensions of technology, people, and institutions, Proceedings of the 12th Annual International Conference on Digital Government Research (pp. 282-291).

[12] Vanolo, A. (2013). Smart mentality: The smart city as disciplinary strategy, urban studies. 1-16. D0I: $10.1177 / 0042098013494427$.

[13] Giffinger, R., Fertner, C., Kramar, H., Kalasek, R., Pichlermilanovic, N., \& Meijers, E. (2007). Smart cities: Ranking of European medium sized cities, Vienna University of Technology. Retrieved from the website: http://www.smartcities.eu/download/smart_cities_final_report.pdf

[14] Hollands, R. G. (2008). Will the real smart city please stand up? Intelligent, progressive or entrepreneurial. City, 12(3), 303-320.

[15] Florida, R. (2002). The Rise of the Creative Class. New York: Basic Books.

[16] Douay, N. (2014). Les usages du numérique dans le débat public. Devenirs urbains, Paris, Presses des MINES, collection Territoires Numériques, GRICO. Retrieved from the website: http://www.grico.fr/wp-content/uploads/2017/03/Devenirs-urbains-DOUAY-V.pdf

[17] Chrislip, D. (2002). The collaborative leadership fieldbook: A guide for citizens and civic leaders. Jossey-Bass. San Francisco, CA.

[18] Kitchin, R. (2014). The real-time city? Big data and smart urbanism. GeoJournal, 79, 1-14, DOI 10.1007/s10708-013-9516-8.

[19] Batty, M., Axhausen, K. W., Giannotti, F., Pozdnoukhov, A., Bazzani, A., Wachowicz, M., Ouzounis, G., \& Portugali, Y. (2012). Smart cities of the future. European Physical Journal Special Topics, 214(1), 481-518.

[20] Schaffers, H., Komninos, N., Pallot, M., Trousse, B., Nilsson, M., \& Oliveira, A. (2011). Smart cities and the future internet: Towards cooperation frameworks for open innovation. Future Internet Assembly, 431-446. LNCS: Springer

[21] Hancke, G. P., Carvalho, E. S. B., Hancke, G. P. J. R. (2013). The role of advanced sensing in smart cities. Sensors, 13(1), 393-425. 
[22] Townsend, A. (2013). Smart cities: Big data, civic hackers, and the quest for a new utopia. New York: W.W. Norton \& Co., 400 p.

[23] Giffinger, R., \& Lü, H. (2015). The smart cities perspective: A necessary change from technical to urban innovation. Fondazione Giangiacomo Feltrinelli. Retrieved from the website: http://www.scuoladiculturapolitica.it/sitoSCP2016/documentazione/Modulo6-The-Smart-City-persp ective-Rudolf-Giffinger-Hui-Lu.pdf

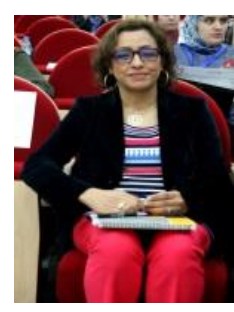

Hanane Rochdane is a full professor joining the university in 2005, where she served as professor of Business Intelligence and Corporate Strategy at ENCG Casablanca. Dr. Rochdane holds a PhD degree from Hassan 2 University Casablanca - Morocco. She is also the head of bussines Department. She has scientific contributions in the field of SME strategy (Franchise- Human Ressources ...). Dr. Rochdane's recent research focuses on Business intelligence and smart cities.

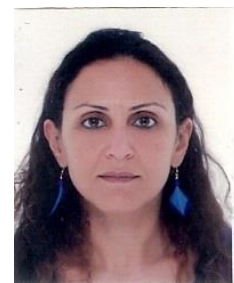

Siham Hamdani is a full professor joining ENCG Casablanca in 2017. She holds a PhD degree from Cadi Ayyad University Marrakech-Morocco (2016). The research focus was on sustainable microfinance and global performance of microfinance institutions (MFIs). Dr. Hamdani's recent research focuses on developing a decision-making support tool measuring the global performance of MFIs. 